\title{
A Literature Review of Non-Surgical Intervention for the Treatment of Idiopathic Talipes Equinovarus: A Podiatric Perspective
}

\author{
by Janet McGroggan, BSc(Hons) ${ }^{1} \otimes$, Gloria Dunlop ${ }^{2}$
}

The Foot and Ankle Online Journal 3 (10): 2

This article aims to discuss the current surgical and non-surgical interventions in the treatment of idiopathic talipes equinovarus. It examines the literature from 1964 to the present day and includes a detailed anatomical description of the condition. The treatment of this condition has evolved from complicated surgical procedures with low long term success rates to less traumatic closed treatments with good outcomes. The latter, specifically the Ponseti Method of treatment, has been practiced by orthopaedic surgeons in the United Kingdom for seven years now and this article examines the podiatrist's potential role in the management of this lower limb complaint.

Key Words: Clubfoot, Idiopathic talipes equinovarus

Published: October, 2010

This is an Open Access article distributed under the terms of the Creative Commons Attribution License. It permits unrestricted use, distribution, and reproduction in any medium, provided the original work is properly cited. (The Foot and Ankle Online Journal (www.faoj.org)

$\mathrm{I}$ diopathic talipes equinovarus (ITEV) is characterised by the ankle in a plantarflexed and inverted position with the heel, midfoot and forefoot adducted and inverted producing a cavus deformity. ${ }^{1}$ The Achilles tendon acts as an invertor ${ }^{2}$ and the calf muscles are shortened. ${ }^{3}$ ITEV, more commonly known as clubfoot, is a disorder affecting one or both lower limbs with fifty percent of cases being bilateral. Worldwide statistics show an incidence ratio of 1.2 babies affected in every 1,000 live births ${ }^{4}$ with a 2:1 male:female ratio. ${ }^{5}$ Bakalis, et al., reported in their retrospective study that of 103,228 routine ultrasound foetal scans taken between January 1991 and October 2000 in three separate London teaching hospitals, $0.1 \% \quad(n=107)$ showed talipes equinovarus.

Address correspondence to: Janet McGroggen

janetmcgroggan@hotmail.co.uk

\footnotetext{
${ }^{1}$ Private Practice, Instep Podiatry Ltd, 26 Greenwood Street, Altrincham, Cheshire, WA14 1RZ.

${ }^{2}$ Lecturer, School of Health Sciences, Subject area of Podiatry, Queen

Margaret University, Edinburgh.
}

The scans were observed at 18-23 weeks of foetal gestation with occurrence being bilateral in 64 cases and unilateral in 43 . The researchers reported $51.4 \%$ of these cases were idiopathic and $48.6 \%$ were associated with other pathologies. ${ }^{6}$ Idiopathic talipes equinovarus has a familial link and displays clear racial prevalence $^{7}$ however, the reason for the abnormal development is still unkown. ${ }^{4}$ In third world countries ITEV is frequently left untreated and affected people will suffer diminished mobility, ulcerations from abnormal weight bearing and be socially ostracised. In the United Kingdom (UK) ITEV has historically been treated primarily through orthopaedic surgery until around 2003 when non surgical methods became more widely available. 

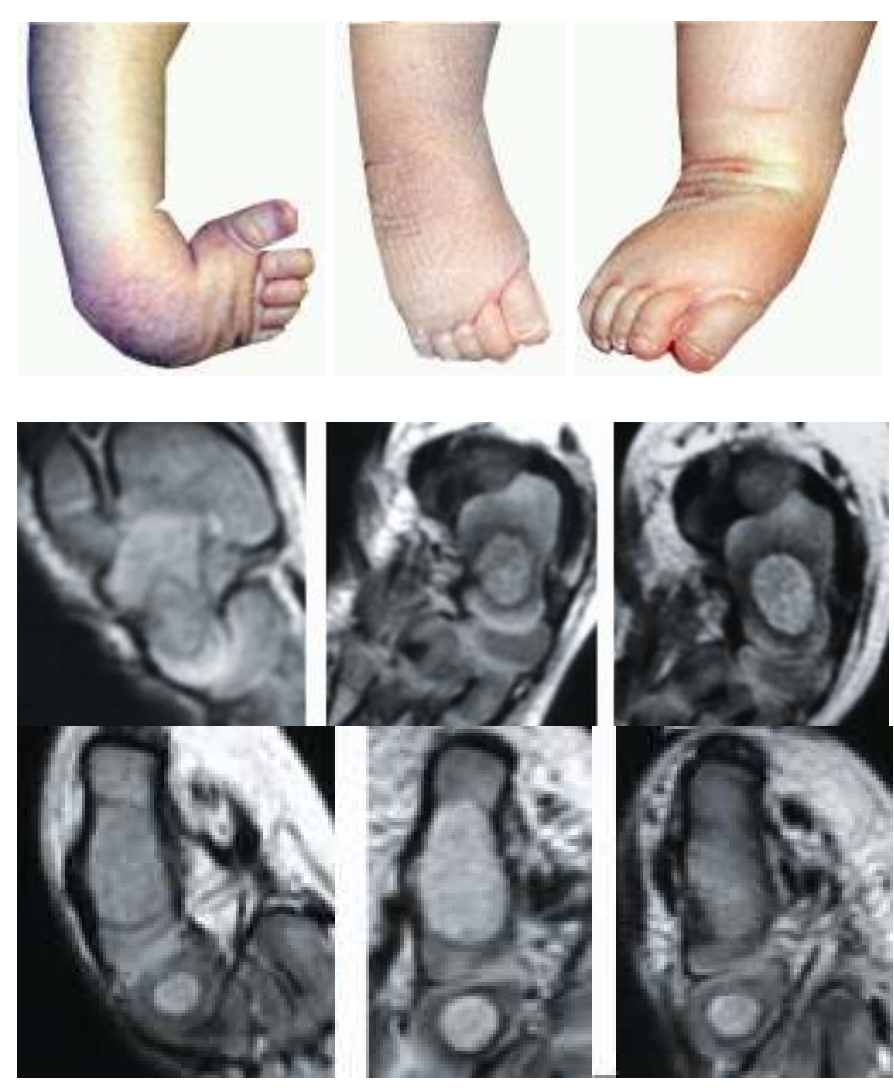

Figure 1 The foot before, during and after treatment. Before treatment, the navicular is displaced to the medial side of the head of the talus. Note how this relationship normalizes during cast treatment. Similarly, the cuboid becomes aligned with the calcaneus during the same cast treatment. Images and description courtesy of www.Global HELP.org .

ITEV is a congenital dysplasia which affects all tissue below the knee. ${ }^{4}$ In a two part anatomical study ${ }^{8,9}$ Windisch, et al., dissected seven foetal feet affected with ITEV aborted in weeks 27-36 of gestation and compared the pathoanatomy with two anatomically normal feet in weeks 27 and 36 of gestation. When describing the bone and joint relationships the authors reported a talar neck-troclea angle of $37^{\circ}$ to $41^{\circ}$ in ITEV compared to $27^{\circ}$ to $33^{\circ}$ in normal feet. Deviation of the talar neck relative to the body was $28^{\circ}$ to $43^{\circ}$ in ITEV compared to $22^{\circ}$ to $24^{\circ}$ in normal feet. The posterior surface of the talus was flat and triangular with the subtalar joint unattainable. The talar head turned along a longitudinal axis opposite to that in the normal foot.
The researchers found the anterior surface of the calcaneus to be flat, medially twisted and orientated upwards, although there was no significant difference in its angle of torsion to that of a normal foot. They concluded that an ossification disturbance of the calcaneus was the primary fault which then influences the varus position of the foot. The soft tissues merely conform to the misshapen bones. The medial ligaments are shortened and thickened, and depending on the severity of the club foot, the tendons of tibialis posterior, flexor hallucis longus and flexor digitorum longus can be wrapped up in a fibrotic mass.

In contrast, Bensahel, et al., found that the midtarsal joint played a major role in ITEV. ${ }^{10}$ They noted that the tibialis posterior turns the talo-navicular joint towards supination with the mid and forefoot following the deviation. This allows the talus to become unstable and the calcaneus to be deviated towards an equinus and varus position. Again the surrounding soft tissues contracts and increases the deformity. Calf muscle atrophy is usual in a limb affected by ITEV ${ }^{4,5}$ with the triceps surae and the tibialis posterior affected the most. ${ }^{7}$ Measurements ranging from $1.25 \mathrm{~cm}$ to $10 \mathrm{~cm}$ difference in the circumference of the calf muscle have been reported between the affected limb and the unaffected limb in unilateral cases. $^{2}$

In her research Whynne-Davis ${ }^{2}$ reported an average limb length discrepancy of $2.5 \mathrm{~cm}$ in 47 unilateral cases of ITEV as a result of shortened bones. This shortening may occur in any one site: femur, tibia, fibula and any of the bones of the foot. Less than half the males studied were affected but all the females were affected in this study which likely is due to the earlier closing of the female epiphyses. Further studies have reported associated musculoskeletal abnormalities occurring in patients with ITEV such as internal tibial torsion and internal femoral torsion. ${ }^{11}$

Eighty nine to ninety percent of ITEV cases present with an absent or reduced anterior tibial artery. ${ }^{12,13}$ In such cases the artery is always hypoplasic and stops at the level of the distal tibial epiphysis. 
This phenomena is only seen in up to $3.5 \%$ of normal feet although difficulties have been reported in interpreting the arteriograms due to the rotation of the feet. ${ }^{14}$ Preservation of four persistent primitive arteries have also been reported the embryonic interosseus, tibial posterior superficialis, peronea posterior superficialis and ramus communicans inferior arteries. ${ }^{13}$ There may also be absence or reduction of the posterior tibial artery and in these cases the peroneal artery becomes dominant. ${ }^{11}$ Research shows not only are the distal vessels affected by hypoplasia, ${ }^{15}$ but the proximal deep femoral and popliteal arteries also display circulatory disturbances. It is possible that an arterial aberration in the sixth and eighth week of gestation is related to the positioning of the calcaneus in equinus. ${ }^{16}$ All foetal feet resemble ITEV at this point of development and although some previous studies have reported no vascular anomalies in still born infants with ITEV, ${ }^{12}$ other research studies have identified an interruption in foot development during the ninth week of gestation. ${ }^{17,18}$ which may provide defective positional information preventing the foot from de-rotating into a normal position. Researchers have claimed that limbs affected show fewer fibroblasts, smaller cells and less cytoplasmic volume suggesting cellular hypoplasia. ${ }^{19}$ It has also been suggested that ITEV may result from growth of the anterolateral foot growing round the stunted posteromedial foot. ${ }^{17}$ This theory suggests a neural abnormality may be present, since muscle fibre type is neurally determined.

\section{Surgical interventions for ITEV}

Surgical intervention is normally carried out before the child is twelve weeks old. ${ }^{20}$ A complete subtalar release $^{21}$ is an extensive soft tissue surgical procedure that is only advised when the foot is at least eight centimetres long. During surgery the talus and calcaneus are repositioned and post operatively the limb is cast with the knee flexed at $90^{\circ}$ and the foot externally rotated at a 10 degree angle to the knee. The limb is then elevated for 10 days. Further casts are applied as an outpatient until six weeks after the procedure. Foot orthoses are then worn at night and straight last shoes during the day.
The parents will perform physiotherapy on the affected limb for two years post operatively. Advantages of the subtalar release are to produce a high degree of correction as well as alignment between the foot and leg. Disadvantages include post operative scarring which may be so extensive that subsequent soft tissue procedures are difficult. There is also a tendency to over correct with the subtalar release and rarely (less than 1/1,000) ischemic necrosis post operatively may develop due to the poor vascular perfusion of the affected limb. ${ }^{22}$

The posteriomedial release is an alternative soft tissue surgical procedure in which the tendo calcaneus is lengthened leaving its lateral attachment intact. Posterior excision of the ankle capsule and the talocalcaneal capsule, including cutting the calcaneofibular ligament, and the tibialis posterior tendon is divided. If necessary the flexor hallucis longus tendon is lengthened and the plantar fascia released including any small muscles arising from the calcaneum. The posterior component of the medial ligament of the ankle is brought forward. Post operatively the limb is cast with the knee in flexion and the foot in dorsiflexion for five days. The limb is then strapped for seven to ten days until $20^{\circ}$ of dorsiflexion is attained. At this point splints are applied and worn continuously until the child is walking. Splints are then reduced to sleep times. ${ }^{20}$ This procedure aims to prevent the pes cavus and metatarsus adductus deformities which occur as a result of over correction after a complete subtalar release. $^{23}$ The reported success rates of the posteriomedial release vary from $50 \%-84 \%{ }^{23,24,25}$ This can be compared to a reported poor result in $15 \%$ of cases treated with a complete subtalar release. ${ }^{23}$ A 30 year follow up of 73 feet treated with extensive soft tissue release concluded that repeated surgery can result in a stiff, painful and arthritic foot causing significant impaired quality of life. ${ }^{26}$ 


\section{Non Surgical Interventions for ITEV}

The French Functional method is a non surgical method of correction commonly used today. ${ }^{27}$ This method was developed in the 1970's ${ }^{28}$ and consists of daily gentle mobilization and stretching of contracted tissues in order to stimulate and strengthen weakened muscles. Taping and splinting are used to maintain the correction'. ${ }^{29}$ The treatment aims to obtain full correction in five months. The parents are taught the technique to continue at home until the child is walking. A splint is then used until the child is two or three years old to prevent relapse.

The Ponseti method of correction is currently the most popular closed technique. ${ }^{27,30}$ Gentle sequential manipulation of the foot is performed to achieve a plantigrade, functional foot. ${ }^{29}$ (See images: Images and description courtesy of www.Global HELP.org.) Photographs and images describe the foot before, during and after treatment. Before treatment, the navicular is displaced to the medial side of the head of the talus. Note how this relationship normalizes during cast treatment. Similarly, the cuboid becomes aligned with the calcaneus during the same cast treatment (Images and description courtesy of www.Global HELP.org.) (Fig. 1) The deformities are dealt with in the following order, cavus, adductus, varus, equinus, and serial casting, with casts used to immobilise the knee at right angles while the leg is rotated to correct tibial torsion. ${ }^{31}$ This process is repeated weekly for five or six weeks until the anterior calcaneus can be abducted from underneath the talus allowing the foot to be safely dorsiflexed without crushing the talus. At this point a Achilles tenotomy may be required to completely correct the equinus deformity producing an average improvement in the lateral tibiocalcaneal angle of $16.9^{\circ} .{ }^{32}$ The foot is then cast again for three weeks by which time the defect in the tendon should be healed. ${ }^{33}$ The child must then wear 'boots and bar' splints (Denis-Browne splints) day and night for 10 weeks and then during sleep until the child is four years old to prevent relapse. ${ }^{33}$ The result is a foot which may appear overcorrected however as the child grows and walks this overcorrection relaxes into a normal foot.
Complications may result with the Ponseti method if the practitioner does not manipulate sequentially. ${ }^{34}$ Such an error can usually be corrected with further serial casting if detected early enough. However, if the talus gets crushed or a rocker bottom deformity develops, ${ }^{35}$ surgery will be required. Lack of compliance precedes the majority of relapses as the child may have trouble sleeping wearing the DenisBrown splints therefore parental education is vital. ${ }^{34}$ Other closed methods such as the 'extra space cast correction technique' have been documented ${ }^{36}$ however the Ponseti method is emerging as the most popular manageable treatment routine which has an average $70 \%$ success rate $^{27,29}$ and produces positive long term results in foot function and aesthetics. 27,37,38 Abnormalities such as knee hyper-extension, equinus gait and foot drop are not reported with the Ponseti method but have been reported with other manipulation techniques.

Currently clinics providing the Ponseti treatment generally comprise of an orthopaedic surgeon, physiotherapists, nurses and an orthotist at the stage of splinting. However the Ponseti method has been extended to other healthcare professionals which has already been trialled successfully in the UK within two separate secondary care settings. ${ }^{39,40}$ Kampa, et al., ${ }^{40}$ used a multidisciplinary team comprising of junior doctors, physiotherapists, nurses and plaster technicians or orthotists. They concluded that the combined approach of a multidisciplinary team and a surgeon when necessary was a success. Docker, et al., ${ }^{39}$ used a team of trained physiotherapists who referred only to the orthopaedic surgeons in the case of complications or the need for a tenotomy. Tenotomies in this study were carried out under general anaesthetic although a local anaesthetic is recommended. ${ }^{41}$ A significant difference in the number of tenotomies required between the two groups was reported in favour of the physiotherapy department. The authors hypothesised that this may be due to the treatment initiating at an earlier stage. 
The Ponseti method would be equally relevant and applicable to podiatry practice as Podiatrists already treat patients with surgically corrected ITEV as part of routine clinical practice, already work in multidisciplinary teams, have extensive specialist knowledge in anatomy and biomechanics of the lower limb and foot, and care on a regular basis for patients with a broad range of physically disabling conditions. The adaptation and the inclusion of current podiatry skills in biomechanical diagnosis, foot casting and orthoses manufacture into the multidisciplinary approach to the Ponseti method, is highly likely to augment delivery of the treatment technique and improve the availability of Ponseti clinics. Having multidisciplinary clinics available at a local level has the potential to reduce the weekly journey time for parents and children making the experience less stressful. As parent education is key to the treatment's success, having podiatrists available close to home for mid week visits to respond to problems when they arise is likely to reduce the long waiting times in out patients departments which is already a problem cited by both Docker, et al., ${ }^{39}$ and Kampa, et al., ${ }^{40}$ Docker, et al., also suggested that the earlier intervention of the multidisciplinary team reduced the number of tenotomies required, again cutting the overall healthcare costs.

Halananski, et al., ${ }^{42}$ compared the resource utilization between the Ponseti method and the standard surgical routes and found a significant difference in the use of resources between the two methods. He did however highlight difficulties in the study as non monetary resources were difficult to quantify. A similar in depth study would be proposed to compare the costs of a surgically led Ponseti clinic with a multidisciplinary Ponseti clinic which ideally should also included a podiatrists as a member of the team.

\section{Conclusion}

It is proposed that the inclusion of podiatry skills to the Ponseti method for the treatment of ITEV, would enhance the continuity of care for the patients in the long term in the assessment and monitoring of post operative care and in identifying further intervention if and when necessary.
Using podiatrists to practice the Ponseti method in a multidisciplinary setting has the potential to develop a more foot focused, cost effective, and patient centred practice and it is proposed that future research into the efficacy and the cost efficiency of the Ponseti method will include the professional and clinical skills of the podiatrist.

The authors invite other clinicians to write in expressing their views on podiatry and the Ponseti method and discuss research results pertaining to this literature review.

\section{References}

1. Pryor GA, Villar RN, Ronen A, Scott PM. Seasonal variation in the incidence of congenital talipes equinovarus. JBJS 1991 73B (4): 632-634.

2. Wynne-Davies R. 1964. Talipes equinovarus: a review of eighty-four cases after completion of treatment. JBJS $196446 \mathrm{~B}$ (3): 464-476.

3. Ippolito E, De Maio F, Mancini F, Bellini D, Orefice A. Leg muscle atrophy in idiopathic congenital clubfoot: is it primitive or acquired? J Childrens Orthopaedics 2009 3: 171-178.

4. Falks S, Luther B. Changing paradigm for the treatment of clubfoot. Orthopaedic Nursing 2005 24(1): 25-30.

5. Vitale M. Clubfoot. EP Magazine 2007 March: 48-50. 6. Bakalis S, Sairam S, Homfray T, Harrington K, Nicholaides K, Thilaganthan B. Outcome of antenatally diagnosed talipes equinovarus in an unselected obstetric population. Ultrasound Obstetric Gynaecology 2002 20: 226-229.

7. Wang J., Palmer R.M., Chung C.S. 1988. The role of major gene in clubfoot. Am J Human Genetics 198842 772-776. 8. Windisch G. Anderhuber F, Haldi-Brändle V, Exner GU. Anatomical study for an updated comprehension of clubfoot.

Part I: Bones and joints. J Childrens Orthopaedics 2007 1: 69-77. 9. Windisch G. Anderhuber F, Haldi-Brändle V, Exner GU. Anatomical study for an updated comprehension of clubfoot. Part II: Ligaments, tendons and muscles. J Childrens Orthopaedics 2007 1: 79-85.

10. Bensahel H, Jehanno P, Benaroya A. Adduction in clubfoot. In: Bensahel H, Kuo KN, Lehman. Fifth Annual Clubfoot Congress IFPOS \& ICFSG, 2008; August 27-28, Hong Kong. J Childrens Orthopaedics 2009 3: 67-83.

11. Howlett JO, Vincent SM, Bjornson K. The association between idiopathic clubfoot and increased internal hip rotation. Clin Orthopaedic Rel Res 2009 467: 1231-1237.

12. Dobbs MB, Gordon JE, Schoenocker PL. Absent posterior tibial artery associated with idiopathic clubfoot. JBJS 2004 86A: 599-602. 
13. Hootnick DR, Dobbs MB, Crider RJ. Are talipes equinovarus and congenital fibular dysplasia different manifestations of aberrant vasculogenesis? In: Bensahel $\mathrm{H}$, Kuo KN, Lehman. Fifth Annual Clubfoot Congress IFPOS \& ICFSG, August 27-28, 2008, Hong Kong. J Childrens Orthopaedics 2009 3:67-83.

14. Greider T D, Siff SJ, Gerson P, Donovan MM. Arteriography in club foot. JBJS 1982; 64: 837-840. 15. Klychkova IJ. Clinical and physiological examination of congenital clubfoot (principles and results). In: Bensahel H, Kuo KN, Lehman. Fifth Annual Clubfoot Congress IFPOS \& ICFSG, August 27-28, 2008, Hong Kong. J Childrens Orthopaedics 2009 3:67-83.

16. Crider RJ, Hootnick DR, Dobbs MM, Seimon L. Do talipes equinovarus (TEV) and congenital vertical talus (CVT) have a common aetiology? In: Bensahel H, Kuo KN, Lehman. Fifth Annual Clubfoot Congress IFPOS \& ICFSG, August 27-28, 2008, Hong Kong. J Childrens Orthopaedics 2009 3:67-83. 17. Rebbeck TR, Dietz FR, Murray JC. A single-gene explaination for the probability of having idiopathic talipes equinovarus. Am J Human Genetics 1993 52:1051-1063. 18. Stabile RJ, Giorgini RJ. A review of talipes equino varus. Podiatry Management 2009 Feb: 167-174.

19. Kruse LM, Bobs MB, Gurnett CA. Polygenic threshold model with sex dimorphism in clubfoot inheritance: the Carter effect. JBJS 2008; 90A: 2688-2694.

20. Green ADL, and Lloyd-Roberts GC. The results of early posterior release in resistant club feet. JBJS 1985 6B: 588-593. 21. Simons GW. Complete subtalar release in club feet. Part $1-$ A preliminary report. JBJS 1985 67A: 1004-1055.

22. Hootnick DR, Dobbs MB, Crider RJ. Review of ischemic necrosis following clubfoot surgery with case of retained primitive arterial rete. In: Bensahel H, Kuo KN, Lehman. Fifth Annual Clubfoot Congress IFPOS \& ICFSG, August 27-28, 2008, Hong Kong. J Childrens Orthopaedics 2009 3: 67-83. 23. Deniz G, Bombaci H, Tuygun H, Görgeç M, Köse O, Yanik HS. Long-term results of extensive surgical dissection in the treatment of congenital clubfoot. Acta Orthopaedica Traumatologica Turcica 2008 42(1):44-52.

24. Prichasuk S, Mulpruok P. Problems in surgical treatment of congenital clubfoot. J Medical Association Thailand 1992 75(1):106-111.

25. Macnicol MF, Nadeem RD, Forness M. Functional results of surgical treatment in congenital talipes equinovarus (clubfoot): a comparison of outcome measurements. J Paediatric Orthopaedics 2000 9(4): 285-292.

26. Dobbs MB, Nunley R, Shoenecker PL. Long-term follow up of patients with clubfeet treated with extensive soft-tissue release. JBJS 2006 88A:986-996.

27. Richards BS, Faulks S, Rathjen KE, Karol LA, Johnston CE, Jones SA. A Comparison of two nonoperative methods of idiopathic clubfoot correction: The Ponseti method and the French Functional (physiotherapy) method. JBJS 2008 90A: 2313-2321.

(C) The Foot and Ankle Online Journal, 2010
28. Bensahel H, Bienayme B, Jehanno P. History of the functional method for conservative treatment of clubfoot. J Childrens Orthopaedics 2007 1: 175-176.

29. Faulkes S, Richards S. Clubfoot treatment: Ponseti and French functional methods are equally effective. Clin Orthopaedic Rel Res 2009 467: 1278-1282.

30. Changulani M, Garg NK, Rajagopal TS, Bass A, Nayagam SN, Sampath J, Bruce CE. Treatment of idiopathic clubfoot using the Ponseti method. JBJS 2006; 88B: 1385-1387.

31. Ponseti IV, Smoley EN. Congenital club foot: the results of treatment. JBJS 1964 45: 261-344.

32. Radler C, Manner HM, Suda R, Burgardt R, Herzenberg JE, Ganger R, Grill F. Radiographic evaluation of idiopathic clubfeet undergoing Ponseti treatment. JBJS 2007 89A: 1177-1183. 33. Ponseti I, Morcuende J, Mosca V, Pirani S, Dietz F, Herzenberg J, Weinstein S, Penny N, Steenbeek M. In: Staheli. L. ed. Clubfoot: Ponseti Management. $2^{\text {nd }}$ ed. [electronic book] Global-HELP publications. Available from: http://www.globalHELP.org [Accessed September 26 2008]. 34. Goksan SB. Treatment of congenital clubfoot with the Ponseti method. Acta Orthopaedica Traumatologica Turcica, 2002 36: 281-287.

35. Wicart P, Koureas, G Seringe R. Rocker bottom deformity: a complication of idiopathic congenital clubfoot conservative treatment. In: Bensahel H, Kuo KN, Lehman. Fifth Annual Clubfoot Congress IFPOS \& ICFSG, August 27-28, 2008, Hong Kong. J Childrens Orthopaedics 2009 3: 67-83.

36. Baindurashvili AG, Rumyantsev NJ, Omarov GG. Extra space casting technique in clubfoot: 20 years of experience. In: Bensahel H, Kuo KN, Lehman. Fifth Annual Clubfoot Congress IFPOS \& ICFSG, August 27-28, 2008, Hong Kong. J Childrens Orthopaedics 2009 3: 67-83.

37. Ippolito E, Farsetti P, Caterini R, Tudisco C. Long-term comparative results in patients with congenital clubfoot treated with two different protocols. JBJS 2003 85A: 1286-1294. 38. El-Hawary R, Karol LA, Jeans KA, Richards BS. Gait analysis of children treated for clubfoot with physical therapy or the Ponseti cast technique. JBJS 2008 90A: 1508-1516.

39. Docker CEJ, Lewthwaite S, Kiely NT. Ponseti treatment in the management of clubfoot deformity - a continuing role for paediatric orthopaedic services in secondary care centres. Annals of the Royal College of Surgeons of England 2007 89(5): 510512.

40. Kampa R, Binks K, Dunkley M, Coates C. Multidisciplinary management of clubfeet using the Ponseti method in a district general hospital setting. J Childrens Orthopaedics 2008 2: 463467.

41. Bor N, Katz Y, Vofsi O, Herzenberg JE, Zuckerberg AL. Sedation protocols for Ponseti clubfoot Achilles tenotomy. J Childrens Orthopaedics 2007 1: 333-335.

42. Halanski MA, Huang J, Walsh SJ, Crawford HA. Resource utilization in clubfoot management. Clin Orthopaedic Rel Res 2009 467: 1171-1179. 